\title{
Drug-induced subacute cutaneous lupus erythematosus associated with docetaxel chemotherapy: a case report
}

\author{
Noelle Y Wong ${ }^{1}$, Laurie M Parsons ${ }^{2}$, Martin J Trotter ${ }^{3}$ and Roger Y Tsang ${ }^{4 *}$
}

\begin{abstract}
Background: Drug-induced subacute cutaneous lupus erythematosus is an uncommon disorder associated with the use of pharmacological agents including systemic chemotherapy.

Case presentation: We report a case of docetaxel-induced subacute cutaneous lupus erythematosus in a 60-yearold Caucasian female with Sjögren's syndrome diagnosed 2 months after receiving docetaxel as part of the adjuvant FEC-D (5-fluorouracil, epirubicin, cyclophosphamide, docetaxel) chemotherapy protocol for early stage breast cancer. Although the exact mechanisms behind the autoimmune response elicited by docetaxel are unclear, the involvement of anti-SSA/Ro antibodies has been implicated.

Conclusion: This case highlights the symptom severity and clinical course of docetaxel-induced subacute cutaneous lupus erythematosus, and highlights the importance of recognizing this uncommon but potentially severe chemotherapy-associated cutaneous reaction.
\end{abstract}

Keywords: Drug-induced subacute cutaneous lupus erythematosus, SCLE, Docetaxel, Chemotherapy, Drug reaction, Breast cancer, Sjögren's syndrome

\section{Background}

Subacute cutaneous lupus erythematosus (SCLE) is a type of cutaneous lupus erythematosus, most commonly characterized by photodistributed, non-scarring, papulosquamous or polycyclic annular plaques. SCLE is often associated with high titers of anti-SSA/Ro antibodies in the serum, and roughly $20 \%$ of newly diagnosed cases of SCLE are attributed to a drug or another exacerbating agent [1]. Development of drug-induced SCLE has been linked to a number of pharmacological agents including thiazide diuretics, calcium channel blockers, angiotensin converting enzyme inhibitors, and taxanes [2,3]. Taxanes, such as docetaxel and paclitaxel, belong to the anti-microtubule class of chemotherapeutic agents and are commonly used in the systemic treatment of non-small cell lung cancer, ovarian cancer, breast cancer, and many other solid tumor malignancies [3]. In this case report, we describe a case of docetaxel-

\footnotetext{
* Correspondence: roger.tsang@albertahealthservices.ca

${ }^{4}$ Department of Oncology, Division of Medical Oncology, University of Calgary, Tom Baker Cancer Centre, 133129 St NW, Calgary, Alberta T2N 4N2, Canada

Full list of author information is available at the end of the article
}

induced SCLE in a 60 year old female with Sjögren's syndrome diagnosed 2 months after receiving docetaxel as part of the adjuvant FEC-D (5-fluorouracil, epirubicin, cyclophosphamide, docetaxel) chemotherapy protocol for early stage breast cancer, and highlight its severity, clinical course, and importance in recognizing this uncommon chemotherapy-associated cutaneous reaction.

\section{Case presentation}

A 60-year-old post-menopausal Caucasian woman with Stage IIB (T2 N1) invasive ductal carcinoma of the left breast commenced adjuvant chemotherapy with the FECD (5-fluorouracil, epirubicin, cyclophosphamide for 3 cycles, followed by docetaxel for 3 cycles) protocol with G-CSF support (peg-filgrastim) after undergoing breastconserving surgery and axillary lymph node dissection. Her past medical history is significant for chronic benign neutropenia and Sjögren's syndrome primarily manifested by dry eyes, myalgias, and arthralgias, without a preexisting history of lupus or other connective tissue disorders. She reports no known drug allergies aside from a rash from adhesive tapes, and her medication profile 
consists of duloxetine, hydroxyquinine, and celecoxib. Two days following the administration of the first cycle of FEC chemotherapy, she developed an exanthema described as a mild erythematous maculopapular pruritic rash on her extensor forearms and anterior trunk, which was felt to be characteristic of a typical chemotherapy-associated rash, given its near complete resolution prior to her subsequent chemotherapy cycle. Nonetheless, the rash did recur with subsequent cycles of FEC chemotherapy, and the switchover to docetaxel after 3 cycles of FEC chemotherapy was delayed by 1 week to allow for its improvement with supportive measures including anti-histamines and a topical corticosteroid. The decision was then made to begin her docetaxel treatment with standard dexamethasone premedication. Shortly after the first cycle of docetaxel, however, she developed a moderately severe, erythematous desquamating rash initially located on her forearms and anterior trunk. The severity and extent of this rash differed from that seen with FEC. With the second cycle of docetaxel, despite the addition of a course of prednisone, the rash progressed to involve her scalp, cheeks, ears, neck, back, as well as membranes of the nose and vagina resulting in epistaxis and vaginal bleeding (Figure 1). This was associated with severe burning pains, and facial and periorbital edema. Due to the severity of her presentation, an urgent dermatology consultation was obtained, with a working diagnosis of Stevens - Johnson syndrome (Table 1). A biopsy was performed on her right forearm, and demonstrated an interface dermatitis with dermal mucin deposition (Figure 2). This pathology was consistent with a diagnosis of subacute cutaneous lupus erythematosus, which was felt to be most likely precipitated by the docetaxel exposure. Laboratory and serologic data revealed an ANA speckled pattern with a titre of $1 / 2560$, high positive levels of anti-SSA/Ro 60 antigen at a value of $88 \mathrm{AU} / \mathrm{mL}$ ( $>81 \mathrm{AU} / \mathrm{mL}$ is high positive), moderately positive levels of anti-SSB/La at a value of $66 \mathrm{AU} / \mathrm{mL}$ (moderate range is 51 $80 \mathrm{AU} / \mathrm{mL}$ ), and elevated rheumatoid factor at $113 \mathrm{kU} / \mathrm{L}$. A decision was made to discontinue chemotherapy after the second cycle of docetaxel, and following its discontinuation, the rash fully resolved after two months, with supportive measures including topical betamethasone cream. During her treatment course, no discernible worsening of her Sjögren's syndrome was reported, which may have been underreported due to concurrent chemotherapy-related toxicities.

\section{Conclusions}

Drug-induced SCLE is an uncommon cutaneous reaction associated with chemotherapy use. In the case presented, given the temporal relationship of the patient's dermatological toxicities to her chemotherapy treatment, we postulate that the taxane docetaxel is the most likely culprit. In the current literature, there have been eight reported cases of SCLE associated with docetaxel, and five reported cases of SCLE associated with paclitaxel chemotherapy [1-13]. Many of the patients in these cases had a background of preceding autoimmune disease with positive anti-SSA/Ro antibodies $[1-5,8,10,11]$. It has been suggested that the presence of serum anti-SSA/Ro antibodies
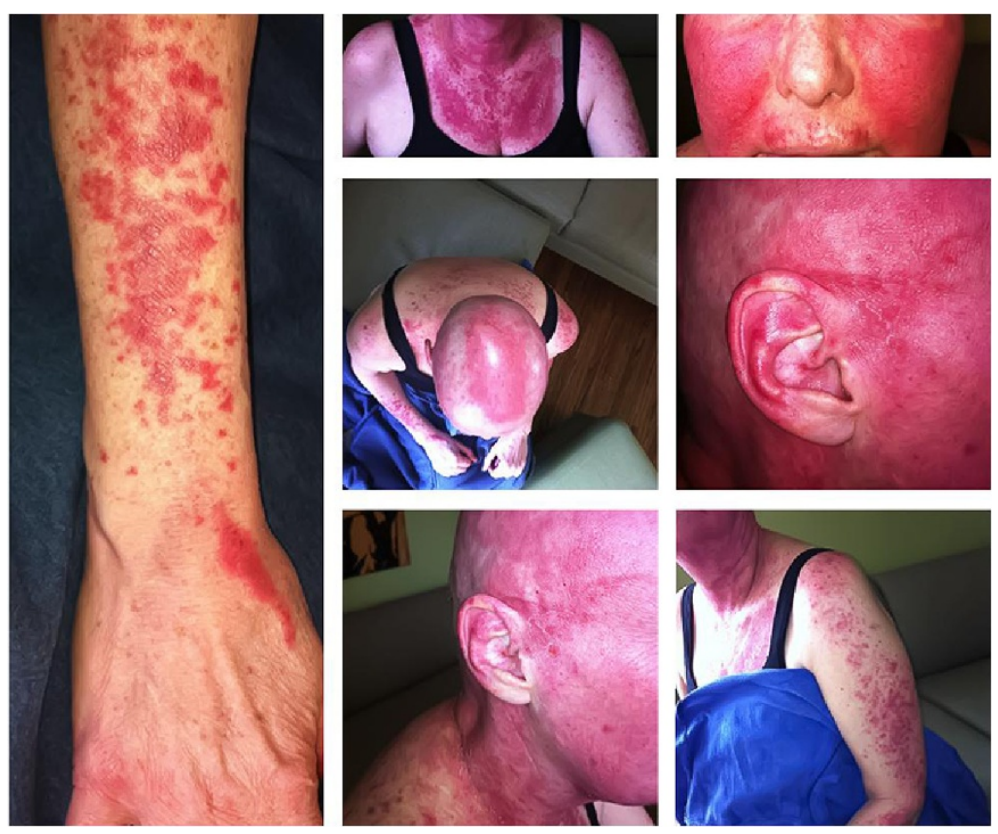

Figure 1 Severe erythematous desquamating rash. The rash involved the forearms, anterior trunk, scalp, cheeks, ears, neck, back, as well as membranes of the nose and vagina resulting in epistaxis and vaginal bleeding. 
Table 1 Clinical and Histological features of Stevens-Johnson syndrome (SJS) and subacute cutaneous lupus erythematosus (SCLE)

\begin{tabular}{|c|c|c|c|}
\hline & Stevens - Johnson syndrome (SJS) & $\begin{array}{l}\text { Subacute cutaneous lupus } \\
\text { erythematosus (SCLE) }\end{array}$ & Case commentary \\
\hline \multirow[t]{4}{*}{$\begin{array}{l}\text { Clinical } \\
\text { features }\end{array}$} & - Mostly drug-related & - May be idiopathic or drug-induced & $\begin{array}{l}\text { Although the rapidity and severity of } \\
\text { symptom progression favored a working } \\
\text { diagnosis of SJS, on clinical grounds it was } \\
\text { not possible to distinguish between SJS } \\
\text { and SCLE in the case presented }\end{array}$ \\
\hline & $\begin{array}{l}\text { - Characterized as dusky erythematous } \\
\text { lesions; lesions tend to be isolated but } \\
\text { can have confluence on the face and } \\
\text { trunk }\end{array}$ & $\begin{array}{l}\text { - Characterized as erythematous, } \\
\text { papulosquamous or polycyclic annular } \\
\text { plaques, typically non-scarring }\end{array}$ & \\
\hline & $\begin{array}{l}\text { - Typically involves the trunk, back, and } \\
\text { extremities including palms and soles, } \\
\text { neck, and face; often associated with } \\
\text { painful mucosal surfaces }\end{array}$ & $\begin{array}{l}\text { - Typically consists of photosensitive regions } \\
\text { with lesions confined to sun-exposed skin } \\
\text { (upper trunk/back, shoulders, extensor } \\
\text { arms, neck, lateral aspects of face) with } \\
\text { mid-facial sparing }\end{array}$ & \\
\hline & $\begin{array}{l}\text { - Usually occurs within } 7 \text { to } 21 \text { days after } \\
\text { initiation of the causative drug }\end{array}$ & $\begin{array}{l}\text { - Latent period between drug } \\
\text { administration and the appearance of } \\
\text { symptoms can range from several weeks } \\
\text { to several years (in drug-induced SCLE) }\end{array}$ & \\
\hline \multirow[t]{2}{*}{$\begin{array}{l}\text { Histological } \\
\text { features }\end{array}$} & $\begin{array}{l}\text { - In early lesions, apoptotic keratinocytes } \\
\text { are observed scattered in the supra-basal } \\
\text { layers of the epidermis }\end{array}$ & $\begin{array}{l}\text { - Epidermal changes and a superficial } \\
\text { lymphocytic infiltrate in the upper dermis } \\
\text { with apoptotic keratinocytes }\end{array}$ & $\begin{array}{l}\text { Histological findings of an interface } \\
\text { dermatitis with dermal mucin deposition is } \\
\text { most consistent with a diagnosis of SCLE }\end{array}$ \\
\hline & $\begin{array}{l}\text { - In late stages, a sub-epidermal blister with } \\
\text { overlying confluent necrosis of the entire } \\
\text { epidermis and spare peri-vascular infiltrate } \\
\text { composed primarily of lymphocytes is seen }\end{array}$ & $\begin{array}{l}\text { - Dermal mucin deposits are commonly } \\
\text { identified }\end{array}$ & \\
\hline
\end{tabular}

may be involved in a mechanism that predisposes patients to a higher risk of developing drug-induced SCLE [4,14]. As taxanes are hypothesized to lead to the appearance or increase in serum anti-SSA/Ro antibodies [10], the risk of drug-induced SCLE would be further heightened given a patient with pre-existing positive titres due to an autoimmune disorder. Docetaxel targets dividing cells and acts to stabilize microtubule assembly, which leads to G2/M phase cell cycle arrest followed by apoptosis [15]. Apoptotic products can then in turn incite an immunogenic response against DNA-histone and RNA-protein complexes [16]. Therefore, in an individual with a pre-existing autoimmune disorder in which antibodies against nucleoproteins already exist (such as anti-SSA/Ro), increased levels of apoptotic products from chemotherapy could stimulate an exacerbated immune response, and manifest as severe cutaneous lesions [17].

Drug-induced SCLE does not differ from idiopathic SCLE in its clinical, immunological, and histopathological characteristics [15]. Therefore, the diagnosis of druginduced SCLE is characterized by the development of diffuse cutaneous lesions following administration of an offending agent, and its resolution upon discontinuation of the drug. In the present case, the clinical and pathological features are compatible with drug-induced SCLE, most likely secondary to docetaxel. The use of dexamethasone likely masked the true severity of the rash. Despite the addition of a course of systemic corticosteroids with prednisone with her second cycle of docetaxel, the rash rapidly progressed. The patient's history of Sjögren's syndrome with high levels of serum anti-SSA/Ro antibodies likely predisposed her to the development of the extensive and severe cutaneous lesions. Anti-SSA/Ro antigens have been seen to preferentially relocate to the surface of cultured keratinocytes that had been irradiated with ultraviolet radiation [18]. It should be noted that her skin lesions were distributed over photo-exposed areas of her body, suggesting that induction of photosensitivity may have been a contributing mechanism to the development of her skin eruptions. Lastly, the patient also had a history of chronic benign neutropenia, and was given peg-filgrastim with her chemotherapy cycles to support her white blood cell and neutrophil counts. The increased number of circulating white blood cells and neutrophils may also have contributed to a heightened immune response, further exacerbating her cutaneous reaction to the docetaxel.

Although SCLE is classically characterized as either idiopathic or drug-induced, there has been sufficient evidence in the literature to consider certain cases of SCLE to have a paraneoplastic etiology [19]. There have been multiple reports of SCLE arising in the setting of internal malignancy including two cases in breast adenocarcinomas [20]. Like other paraneoplastic dermatoses, presentations of paraneoplastic SCLE follow the criteria in that the cutaneous findings appear temporally after development of the malignancy, and their clinical courses typically run parallel 


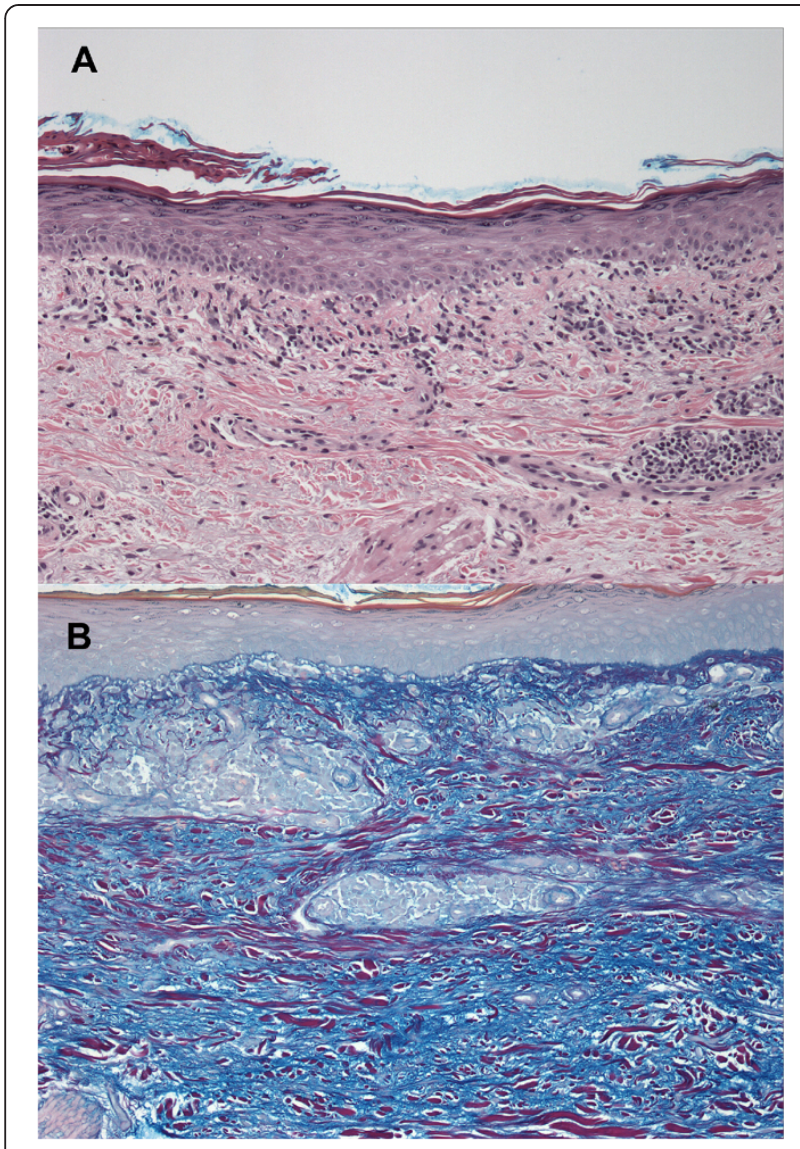

Figure 2 Photomicrographs of a skin biopsy. Photomicrographs show an interface dermatitis with associated mid-dermal peri-vascular lymphocytic inflammation (A: hematoxylin and eosin, 100X) and dermal mucin deposition (B: Hale's colloidal iron, 100X).

[21]. As such, paraneoplastic SCLE tends to resolve after successful treatment of the malignancy. However, because of the role of chemotherapy treatments in causing tumor regression and the timing of its administration, it may sometimes be difficult to differentiate drug-induced SCLE from paraneoplastic SCLE. This is especially true if the appearance of skin eruptions occurs shortly after beginning systemic chemotherapy. However, if the lesions regress quickly after discontinuing chemotherapy, as was observed in this case, then the etiology would be most compatible with drug-induced SCLE. Regardless, it is important to also consider paraneoplastic SCLE in the differential diagnosis.

Drug-induced subacute cutaneous lupus erythematosus (SCLE) is an uncommon but potentially severe disease state associated with docetaxel chemotherapy. The clinician needs to recognize and consider this entity in the differential diagnosis of chemotherapy-associated cutaneous reactions, given its severity, and the importance of discontinuing the offending agent as primary management. Although the exact mechanisms behind drug-induced SCLE remain unclear, patients with a pre-existing autoimmune disorder appear to have a higher incidence when exposed to offending agents including chemotherapy. The identification and discontinuation of the offending agent is essential in the management of drug-induced autoimmune reactions.

\section{Consent}

Written informed consent was obtained from the patient for the publication of this case report and any accompanying images. A copy of the written consent is available for review by the Editor-in-Chief of this journal.

\section{Abbreviations}

SCLE: Subacute cutaneous lupus erythematosus; FEC-D: 5-fluorouracil, epirubicin, cyclophosphamide, docetaxel chemotherapy; G-CSF: Granulocyte colony-stimulating factor; ANA: Anti-nuclear antibody; DNA: Deoxyribonucleic acid; RNA: Ribonucleic acid.

\section{Competing interests}

The authors declare that they have no competing interests.

\section{Authors' contributions}

NY Wong drafted and revised the manuscript. LM Parsons was involved in the dermatological aspects of the case. MJ Trotter was involved in the pathological aspects of the case. RY Tsang provided oncological care of the patient, conceived the case report, and revised the manuscript. All authors read and approved the final manuscript.

\section{Author details}

${ }^{1}$ Faculty of Medicine, University of Calgary, Calgary, AB, Canada. ${ }^{2}$ Department of Medicine, Division of Dermatology, University of Calgary, Calgary, AB, Canada. ${ }^{3}$ Department of Pathology and Laboratory Medicine, University of Calgary, Calgary, AB, Canada. ${ }^{4}$ Department of Oncology, Division of Medical Oncology, University of Calgary, Tom Baker Cancer Centre, 133129 St NW, Calgary, Alberta T2N 4N2, Canada.

Received: 27 May 2014 Accepted: 20 October 2014

Published: 5 November 2014

\section{References}

1. Callen J: Drug-induced subacute cutaneous lupus erythematosus - filling the gap in knowledge. JAMA Dermatol 2013, 149(9):1075-1076.

2. Chen M, Crowson A, Woofter M, Luca M, Magro C: Docetaxel (Taxotere) induced subacute cutaneous lupus erythematosus: report of 4 cases. J Rheumatol 2004, 31(4):818-820.

3. Lebeau S, Tambe S, Sallam M, Alhowaish A, Tschanz C, Masouye I, Borradori L: Docetaxel-induced relapse of subacute cutaneous lupus erythematosus and chilblain lupus. J Dtsch Dermatol Ges 2013, 1109:871-874.

4. Adachi A, Horikawa T: Paclitaxel-induced cutaneous lupus erythematosus in patients with serum anti-SSA/Ro antibody. J Dermatol 2007, 34(7):473-476.

5. Dasanu C, Alexandrescu D: Systemic lupus erythematosus associated with paclitaxel use in the treatment of ovarian cancer. South Med J 2008, 101(11):1161-1162.

6. Funke A, Kulp-Shorten C, Callen J: Subacute cutaneous lupus erythematosus exacerbated or induced by chemotherapy. JAMA Dermatol 2010, 146(10):1113-1116.

7. Gantzer A, Regnier S, Cosnes A, Ortonne N, Wolkenstein P, Bagot M, Duong T: Subacute cutaneous lupus erythematosus and cancer: two cases and literature review. Annales de Dermatologieet de Venereologie 2011, 138(5):409-417.

8. Lamond N, Younis T, Purdy K, Dorreen M: Drug-induced subacute cutaneous lupus erythematosus associated with nab - paclitaxel therapy. Curr Oncol 2013, 20(5):484-487.

9. Lortholary A, Cary-Ten Have Dallinga M, El Kouri C, Morineau N, Ramee J: Paclitaxel-induced lupus. Presse Med 2007, 36(9):1207-1208.

10. Marchetti M, Noland M, Dillon P, Greer K: Taxane associated subacute cutaneous lupus erythematosus. Dematol Online J 2013, 19(8):19259. published online July 2013, doj_19259. 
11. Pham A, Berz D, Karwan P, Colvin G: Cremophor-induced lupus erythematosus-like reaction with taxol administration: a case report and review of the literature. Case Rep Oncol 2011, 4:526-530

12. Renner R, Sticherling M: Incidental cases of subacute cutaneous lupus erythematosus in association with malignancy. Eur J Dermatol 2008, 18(6):700-704

13. Vihinen P, Paija O, Kivisaari A, Koulu L, Aho H: Cutaneous lupus erythematosusafter treatment with paclitaxel and bevacizumab for metastatic breast cancer: a case report. J Med Case Rep 2011, 5:243.

14. Srivastava M, Rencic A, Diglio G, Santana H, Bonitz P, Watson R, Ha E, Anhalt G, Provost T, Nousari C: Drug induced, Ro/SSA-positive cutaneous lupus erythematosus. Arch Dermatol 2003, 139(1):45-49.

15. Lowe G, Henderson C, Hansen C, Sontheimer R: A systematic review of drug-induced subacute cutaneous lupus erythematosus. Brit J Dermatol 2011, 164(3):465-472.

16. Stollar B, Stephenson F: Apoptosis and nucleosomes. Lupus 2002, 11:787-789.

17. Rahman A, Stollar B: Origin and structure of autoantibodies and antigens in autoimmune rheumatic diseases. Lupus 2008, 17:232-235.

18. Igarashi T, Itoh Y, Fukunaga Y, Yamamoto M: Stress-induced cell surface expression and antigenic alteration of the Ro/SSA autoantigen. Autoimmunity 1995, 22(1):33-42.

19. Evans KG, Heymann WR: Paraneoplasticsubacute cutaneous lupus erythematosus: an underrecognized entity. Cutis 2013, 91:25-29.

20. Shaheen B, Milne G, Shaffrali F: Subacute cutaneous lupus erythematosus associated with breast carcinoma. Clin Exp Dermatol 2009, 34:480-481.

21. McLean D: Cutaneous paraneoplastic syndromes. Arch Dermatol 1986, 122:765-767.

doi:10.1186/1756-0500-7-785

Cite this article as: Wong et al:: Drug-induced subacute cutaneous lupus erythematosus associated with docetaxel chemotherapy: a case report. BMC Research Notes 2014 7:785.

\section{Submit your next manuscript to BioMed Central and take full advantage of:}

- Convenient online submission

- Thorough peer review

- No space constraints or color figure charges

- Immediate publication on acceptance

- Inclusion in PubMed, CAS, Scopus and Google Scholar

- Research which is freely available for redistribution 